\title{
Increasing Firm's Innovation Performance through Formal and Informal Integrating Mechanisms
}

\author{
Hang WU \\ Business School, East China University of Political Science and Law, Shanghai, China, 201620 \\ wuhang0503@163.com \\ ${ }^{*}$ Corresponding author
}

Keywords: Innovation performance, Formal knowledge integration, Informal knowledge integration, Knowledge-based view.

\begin{abstract}
There is consensus in the knowledge management literature that knowledge integration mechanism is fundamental for firms to conduct innovation successfully. However, few studies examine the dimensions or characteristics of knowledge integration mechanism and how these mechanisms influence firms' innovation performance. This paper divide knowledge integration into two parts, namely formal knowledge integration and informal knowledge integration, and examines how formal knowledge integration and informal knowledge integration help enhance innovation performance in China's emerging economy. The result shows that formal knowledge integration and informal knowledge integration both are positively related to innovation performance. Theoretical and managerial implications are discussed.
\end{abstract}

\section{Introduction}

Innovation has emerged as a basic foundation for firms to compete with other counterparts in the global markets. Research on the open innovation fields has discovered that external knowledge can promote innovation performance according to the resource-based view [1, 2]. However, the logic of knowledge-based view is that the source of competitive advantage is not knowledge, but knowledge integration [3, 4]. Nowadays, existing research has only proved the importance of knowledge integration, without a distinction between formal and informal knowledge integration and how different knowledge integration matters in firms' innovation $[5,6,7]$.

In order to fill the research gap, this study endeavors to examine how different dimensions of knowledge integration, including formal knowledge integration and informal knowledge integration, affect firms' innovation performance in Chinese context. This research enriches the knowledge integration theory and can guild the firm to establish formal and informal knowledge integration mechanism to enhance innovation performance.

\section{Theory and Hypotheses}

\section{Two Dimensions of knowledge integration mechanism}

The concept of knowledge integration is put forward by Henderson and Clark [8] during the product research. Henderson and Clark [8] argue that the capability to deploy and configure existing knowledge is essential for firms. Kogut and Zander [9] refer it as knowledge integration and define it as the process of recognizing what it has learned and decides how to use it. Grant [3] firstly systematically elaborates on the knowledge integration theory and thinks the advantage comes from knowledge integration, but not knowledge. Zahra et al. [5] refer knowledge integration as the process by which managers inventory, synthesize, and use the knowledge they have gained. De Luca and Atuahene-Gima [7] define knowledge integration as structures and processes, such as the use of documentation and meetings that ensure the capture, analysis, interpretation of knowledge within the firm. In fact, knowledge can he integrated formally or informally [3]. Formal knowledge integration are structures and processes for integrating 
different types of knowledge among different functional units within a firm [10]. Informal knowledge integration is the atmosphere created in the firm to promote knowledge exchange [10].

\section{Formal and informal knowledge integration and innovation performance}

According to the knowledge-based view, knowledge can not be automatically transferred into firms' innovation performance, but must be integrated formally and informally [11, 12]. Knowledge integration mechanism includes two parts, namely formal knowledge integration and informal knowledge integration which increase innovation performance from two aspects. On the one hand, formal knowledge integration mechanism may be considered as important channel through which different functional units can be infused to enhance the likelihood of finding solutions in the product innovation. Through regular and formal face-to-face discussion and meetings about the failed and successful projects between different departments, firms can systematically select and connect knowledge to innovation performance [13, 14]. On the other hand, informal knowledge integration mechanism creates a healthy environment in the firms for employees freely and happily to exchange ideas. Under this conditions, employees will be encouraged to bypass formal communication channels, use informal relationships to get things done, which maintains open communication channels in its operations and finally promote the opportunity-recognizing activities $[15,16]$. Based on these arguments, we propose:

Hypothesis 1: Formal knowledge integration is positively related to innovation performance

Hypothesis 2: Informal knowledge integration is positively related to innovation performance

\section{Methodology}

\section{Sample and Data Collection}

This study used questionnaires to collect data from manufacturing firms in China. Following various efforts, including both formal and informal contacts with the selected firms, we received 219 valid questionnaires, with a response rate of $44.75 \%$. The responding firms were distributed in the electronic information industry (29.68\%), special equipment manufacturing(20.55\%), transportation equipment manufacturing $(12.33 \%)$, ordinary machinery manufacturing $(11.42 \%)$, metal product industry(9.13\%), and others (16.89\%). The results of the Harman's one-factor tests showed that a common method bias is not a problem in our analysis.

\section{Measures}

The dependent variable is innovation performance. Following the approach of Chen et al. [2] Zhang and $\mathrm{Li}$ [1], we used six items to measure innovation performance which mainly describe the speed and quality of innovation compared to industrial counterparts. The specific measurement items can be seen in table 3 . The alpha values for innovation performance is 0.985 , which indicate a good reliability.

The dependent variable is knowledge integration, including formal knowledge integration and informal knowledge integration. Following the approach of Zahra and Nielsen [10] and Zahra et al. [5], we use five items to measure formal knowledge integration which highlights using the system, procedures and rules to capture, interpret, and integrate knowledge, and use four items to measure informal knowledge integration which highlights creating the cultural atmosphere in the firm. The alpha values for formal knowledge integration is 0.962 , and for informal knowledge integration is 0.929 , which indicate a good reliability.

We take the following variables as controls. First, firm size referred to the natural log of the number of full-time employees. The analysis controlled for a company's size because of its potential impact on innovation performance [10]. Second, firm age referred to the number of years since the firm was founded. This study also controlled for age because established companies had more access to external sources [10]. Third, a dummy variable was created for corporate ownership, taking the value 1 if the firm was controlled by state capital, and zero otherwise. We introduce five industry dummy to control the industry effect, with industry 1, 2, 3, 4, 5 indicating electronic information, special equipment manufacturing, transportation equipment manufacturing, percent in ordinary machinery manufacturing, metal product. 


\section{Empirical Results}

\section{Assessment of the Measures}

Table 1 presents the means, standard deviations, and correlations among the variables examined in the study. Formal integration $(r=0.544, \mathrm{p}<0.01)$ and informal integration $(r=0.535, \mathrm{p}<0.01)$ both are positively correlated with innovation performance. Formal integration is positively correlated with informal integration $(\mathrm{r}=0.462, \mathrm{p}<0.01)$. The results of correlation analysis lay a solid foundation for the next multiple regression analysis.

Table 1 Descriptive statistics and pearson correlations

\begin{tabular}{c|c|c|c|c|c|c|c|c|c}
\hline & Mean & S.D. & 1 & 2 & 3 & 4 & 5 & 6 & 7 \\
\hline 1. Firm size & 7.559 & 1.400 & 1 & & & & & & \\
\hline 2. Firm age & 15.54 & 9.158 & $0.405_{* *}$ & 1 & & & & & \\
\hline 3. R\&D intensity & 0.048 & 0.025 & 0.003 & 0.030 & 1 & & & & \\
\hline 4. Corporate ownership & 0.361 & 0.481 & -0.018 & -0.046 & -0.026 & 1 & & & \\
\hline 5. Formal Integration & 4.520 & 1.385 & 0.067 & -0.112 & $0.165_{*}$ & -0.031 & 1 & & \\
\hline 6. Informal Integration & 4.030 & 1.157 & $0.263_{* *}$ & 0.052 & $0.188_{* *}$ & -0.056 & $0.462_{* * *}$ & 1 & \\
\hline 7. Innovation performance & 3.980 & 1.659 & $0.211_{* *}$ & 0.015 & $0.365_{* *}$ & -0.027 & $0.544_{* *} 0.535_{* *}$ & 1 \\
\hline
\end{tabular}

$* * \mathrm{p}<0.01 ; * \mathrm{p}<0.05$ (two-tailed test).

\section{Exploratory Factor Analysis}

We start with exploratory factor analysis using principal axis factoring to uncover the underlying factor structure of the knowledge integration mechanism (as shown in table 2). In line with earlier work by Zahra and Nielsen ${ }_{[10]}$, the rotated factor matrix produced an two-factor solution, accounting for $85.11 \%$ of the total variance. All the items cleanly loaded on the expected factors, without significant cross loadings.

Table 2 Results of factor analysis of integration mechanism

\begin{tabular}{c|c|c}
\hline & Factor 1 & Factor 2 \\
\hline Encourage free exchange of operating and financial information & 0.256 & $\mathbf{0 . 8 8 9}$ \\
\hline Encourage bypassing of formal communication channels & 0.191 & $\mathbf{0 . 8 7 7}$ \\
\hline Stresses informal relationships for getting things done & 0.206 & $\mathbf{0 . 8 7 2}$ \\
\hline Maintains open communication channels in its operations & 0.214 & $\mathbf{0 . 8 9 4}$ \\
\hline Regularly use formal reports and memos to summarize learning & $\mathbf{0 . 8 9 2}$ & 0.243 \\
\hline Regularly hold information sharing meetings & $\mathbf{0 . 9 0 5}$ & 0.254 \\
\hline Actively promote face-to-face discussions for cross-functional teams & $\mathbf{0 . 9 3 1}$ & 0.175 \\
\hline Regularly conduct formal analysis of failing and successful product \\
development projects & $\mathbf{0 . 8 8 8}$ & 0.233 \\
\hline Regularly use of experts and consultants to synthesize knowledge & $\mathbf{0 . 9 1 2}$ & 0.208 \\
\hline Eigenvalue & 5.660 & 2.000 \\
\hline Cumulative \% of variance explained & 62.89 & 22.22 \\
\hline KMO $=0.909$, Approx. Chi-Square=2039.980, $\mathrm{p}<0.001$ & 85.11 \\
\hline
\end{tabular}

\section{Confirmatory factor analysis}

We conducted a confirmatory factor analysis to assess the convergent and discriminant validity of the formal knowledge integration, informal knowledge integration and innovation performance. The 
chi-square value for the model was 176.802, with 87 degrees of freedom. The fit indices of the three-factor confirmatory factor analysis showed that the model fits the data resaonably well, with all indices meeting the respective criteria $\left(\chi_{2} / \mathrm{df}=2.032<3, \mathrm{NFI}=0.962, \mathrm{NNFI}=0.973, \mathrm{CFI}=0.980, \mathrm{IFI}\right.$ $=0.980$, RMSEA $=0.069)$. All the items were loaded significantly on the expected latent constructs, item-construct loadings were high $(\lambda>0.8)$ and significant $(\mathrm{p}<0.001)$, thereby providing evidence of good convergent validity, as shown in table 2 . The results also support the discriminant validity of formal knowledge integration, informal knowledge integration and innovation performance, as the AVE of each construct was far greater than the corresponding inter-construct squared correlations.

Table 3 Measurement scales and properties

\begin{tabular}{|c|c|c|}
\hline Constructs/Measurement items & $\begin{array}{l}\text { Standardized } \\
\text { loadings }\end{array}$ & AVE \\
\hline Formal knowledge integration & & \multirow{6}{*}{0.837} \\
\hline 1. Regularly use formal reports and memos to summarize learning & 0.902 & \\
\hline 2. Regularly hold information sharing meetings & 0.931 & \\
\hline 3. Actively promote face-to-face discussions for cross-functional teams & 0.931 & \\
\hline $\begin{array}{l}\text { 4. Regularly conduct formal analysis of failing and successful product } \\
\qquad \text { development projects }\end{array}$ & 0.891 & \\
\hline 5. Regularly use of experts and consultants to synthesize knowledge & 0.920 & \\
\hline \multicolumn{2}{|l|}{ Informal knowledge integration } & \multirow{5}{*}{0.769} \\
\hline 1. Encourage free exchange of operating and financial information & 0.910 & \\
\hline 2. Encourage bypassing of formal communication channels & 0.859 & \\
\hline 3. Stresses informal relationships for getting things done & 0.848 & \\
\hline 4. Maintains open communication channels in its operations & 0.890 & \\
\hline \multicolumn{2}{|l|}{ Innovation performance } & \multirow{7}{*}{0.916} \\
\hline 1.The number of new products & 0.954 & \\
\hline 2.The ratio of new products sales to total sales & 0.961 & \\
\hline 3.The speed of new product development & 0.949 & \\
\hline 4.The success ratio & 0.955 & \\
\hline 5.The number of patent applications & 0.968 & \\
\hline 6.The novelty of new product & 0.956 & \\
\hline
\end{tabular}

All standardized coefficient loadings are significant at $\mathrm{p}<0.001$.

$\mathrm{AVE}=$ Average variance extracted for each multi-item construct in the research model .

\section{Multiple Regression Analysis}

Table 4 presents the results of the hierarchical multiple regression models. Model 1 only included controls of industry type, firm size, firm age, R\&D intensity, corporate ownership. Model 2 added the main effects of formal integration. Model 3 added the main effects of informal integration. Model 4 added all the main effects of formal integration and informal integration. All the VIF (variance inflation factor) are far less than 10, which indicate multicollinearity is not a problem in our study.

Hypothesis 1 proposes that formal integration is positively related to innovation performance. The results in Model 2 suggest that formal integration $(b=0.484, p<0.001)$ is positively related to innovation performance. Hypothesis 1 is supported. Hypothesis 2 proposes that informal integration is positively related to innovation performance. The results in Model 3 suggest that informal integration $(b=0.451$, $\mathrm{p}<0.001)$ is positively related to innovation performance. Hypothesis 2 is supported. The results in model 4 also prove that formal integration $(b=0.362, p<0.001)$ and informal integration $(b=0.290, p<0.001)$ are both positively related to innovation performance, therefore supporting hypothesis 1 and hypothesis 2 again. 
Table 4 Results of standardized regression analysis

\begin{tabular}{c|c|c|c|c}
\hline & Model 1 & Model 2 & Model 3 & Model 4 \\
\hline & 0.036 & 0.041 & -0.019 & 0.005 \\
\hline Industry 1 & 0.083 & 0.024 & 0.021 & -0.001 \\
\hline Industry 2 & -0.055 & -0.087 & -0.084 & -0.097 \\
\hline Industry 3 & 0.083 & 0.031 & 0.015 & 0.001 \\
\hline Industry 4 & 0.068 & 0.042 & 0.028 & 0.023 \\
\hline Industry 5 & $0.253_{* * *}$ & $0.179_{* *}$ & 0.121 & 0.113 \\
\hline Firm size & -0.106 & -0.036 & -0.068 & -0.030 \\
\hline Firm age & $0.382_{* * *}$ & $0.305_{* * *}$ & $0.292_{* * *}$ & $0.266_{* * *}$ \\
\hline R\&D intensity & -0.015 & -0.004 & 0.011 & 0.010 \\
\hline Corporate ownership & & $0.484_{* * *}$ & & $0.362_{* * *}$ \\
\hline Formal Integration & & & $0.451_{* * *}$ & $0.290_{* * *}$ \\
\hline Informal Integration & 0.202 & 0.418 & 0.379 & 0.477 \\
\hline $\mathrm{R}_{2}$ & & 0.216 & 0.177 & 0.275 \\
\hline$\Delta \mathrm{R}_{2}$ & 0.168 & 0.390 & 0.350 & 0.450 \\
\hline Adjusted R & $5.892_{* * *}$ & $14.964_{* * *}$ & $12.720_{* * *}$ & $17.194_{* * *}$ \\
\hline $\mathrm{F}$ & 2.250 & 2.250 & 2.267 & 2.273 \\
\hline Max VIF & & &
\end{tabular}

\section{Discussion and Conclusion}

\section{Main Findings}

In this study, we examined the relationships between formal knowledge integration, informal knowledge integration and innovation performance. With data on a sample of Chinese manufacturing firms, we found that formal knowledge integration and informal knowledge integration both have significant positive relationships with innovation performance.

\section{Theoretical and Practical Implications}

This study contributes to existing research on the relationship between knowledge integration and innovation performance. Although existing research has demonstrated the importance of knowledge integration, but ignored to uncover the different dimensions of knowledge integration and how different dimensions of knowledge integration affect firms innovation performance. This study fills the research gap by illustrating how a firm's formal knowledge integration and informal knowledge integration affect its innovation performance. Therefore, this study is helpful for the knowledge integration theory.

The study also has practical implications for managers. Managers need to realize the strategic significance of formal knowledge integration and informal knowledge integration for promoting innovation performance. Firms should not only pay enough attention to building formal knowledge integration mechanism by procedures, formal meetings and reports, but also building informal knowledge integration mechanism by creating free cooperating and communication atmosphere.

\section{Limitations and Future Research Directions}

Our study has limitations that need to be addresed in future research. We examined the impact of different knowledge integration mechanisms on innovation performance. Future research can deepens the research from two aspects. On the one hand, we can examine the antecedents of formal and informal knowledge integration mechanism, such as cross-functional collaboration, external knowledge search and so on. On the one hand, future research can examine under what conditions formal and informal knowledge integration mechanism are more conducive to firm's innovation performance.

\section{Acknowledgement}

This research was financially supported by China Post doctoral Science Foundation (2014M561452), and soft science research project in zhejiang province (2014C35012). 


\section{References}

[1] Y. Zhang, H. Y. Li, Innovation search of new ventures in a technology cluster: The role of ties with service intermediaries. Strategic Management Journal. 31 (2010) 88-109.

[2] J. Chen, Y. Chen, W. Vanhaverbeke, The influence of scope, depth, and orientation of external technology sources on the innovative performance of Chinese firms. Technovation. 31 (2011) 362-373.

[3] R. M. Grant, Prospering in dynamically-competitive environments: Organizational capability as knowledge integration. Organization Science. 7 (1996) 375-387.

[4] R. M. Grant, The resource-based theory of competitive advantage: Implications for strategy formulation. California Management Review. 33 (1991) 114-135.

[5] S. A. Zahra, R. D. Ireland, M. A. Hitt, International expansion by new venture firms: International diversity, mode of market entry, technological learning, and performance. Academy of Management Journal. 43 (2000) 925-950.

[6] K-H. Tsai, T. T. Hsu, Cross-Functional collaboration, competitive intensity, knowledge integration mechanisms, and new product performance: A mediated moderation model. Industrial Marketing Management. 43 (2014) 293-303.

[7] L. M. De Luca, K. Atuahene-Gima, Market knowledge dimensions and cross-functional collaboration: Examining the different routes to product innovation performance. Journal of Marketing. 71 (2007) 95-112

[8] R. M.Henderson, K. B. Clark, Architectural innovation: The reconfiguration of existing product technologies and the failure of established firms. Administrative Science Quarterly. 35 (1990) 9-30.

[9] B. Kogut, U. Zander, Knowledge of the firm, combinative capabilities, and the replication of technology. Organization Science, 3 (1992) 383-397.

[10] S. A. Zahra, A. P. Nielsen, Sources of capabilities, integration and technology commercialization. Strategic Management Journal. 23 (2002) 377-398.

[11] G. Hamel, G. K. Prahalad, Competing for the future. Boston: Harvard Business School Press. 1994.

[12] K. B. Kahn, Market orientation, interdepartmental integration, and product development performance. Journal of Product Innovation Management. 18(2001) 314-323.

[13] K. B. Kahn, J. T. Mentzer, Marketing's integration with other departments. Journal of Business Research. 42(1998) 53-62.

[14] M.Song, M. Montoya-Weiss, J. Schmidt, Antecedents and consequences of cross-functional cooperation: A comparison of $\mathrm{R} \& \mathrm{D}$, manufacturing, and marketing perspectives. Journal of Product Innovation Management. 14(1997) 35-47.

[15] M. Song, J. Thieme, J. Xie, The impact of cross-functional joint involvement across product development stages: An exploratory study. Journal of Product Innovation Management. 15 (1998) 289-303.

[16] M. Song, J. Xie, Does innovativeness moderate the relationship between cross-functional integration and product performance? Journal of International Marketing. 8 (2000) 61-89. 